1

2

3

4

5

6

7

8

9

10

11

12

13

14

15

16

17

18

19

20

21

22

23

24

25

26

20

21

2

3

24

25

6

27

Word count: 6424 excluding references

8

Integrating theories of self-control and motivation to advance endurance performance

1

3

4

5

6

7

Word count: 6424 excluding references

9


Abstract

29 Self-control is a burgeoning research topic within sport and motivational psychology.

30 Following efforts to define and contextualize self-control, characteristics of self-control are

31 considered that have important implications for sport performance. We describe and evaluate

32 various theoretical perspectives on self-control, including limited resources, shifting

33 priorities, and opportunity-costs. The research described includes sport-specific research but

34 also studies that focus on general motivational principles that look beyond sport-specific

35 phenomena. We propose that attentional, rather than limited resource, explanations of self-

36 control have more value for athletic performance. Moreover, we integrate self-control ideas

37 with descriptions of motivational phenomena to derive novel hypotheses concerning how

38 self-control can be optimized during sport performance. We explain how minimizing desire-

39 goal conflicts by fusing self-control processes and performance goals can delay aversive

40 consequences of self-control that may impede performance. We also suggest that autonomous

41 performance goals are an important motivational input that enhances the effectiveness of self-

42 control processes by a) reducing the salience of the desire to reduce performance-related

43 discomfort, b) increasing attentional resources towards optimal performance, and c)

44 optimizing monitoring and modification of self-control processes. These extensions to

45 knowledge help map out empirical agenda which may drive theoretical advances and deepen

46 understanding of how to improve self-control during performance.

47

48 Keywords: ego-depletion, motivation, self-regulation, goal conflict, self-determination

49

50

51

52 
Integrating theories of self-control and motivation to advance endurance performance The ability to resist feelings of discomfort and the urge to quit are critical elements of successful sport performance, particularly for athletes who engage in prolonged physiological efforts at high intensity. Succumbing to the urge to relieve the distress, even by minuscule amounts, can be the difference between winning and losing. Indeed, the ability to override natural tendencies may be a key individual difference that separates elite performers from others (Martin et al., 2016; Tajet-Foxell \& Rose, 1995). Despite the importance of this characteristic, it is not well understood; hence, the psychological processes involved have not been appropriately described. We propose that integrating models of self-control and motivation represent a potential solution to this shortcoming. This article begins by defining self-control, outlining the processes involved and contextualizing it within the broader selfregulation construct. We then evaluate whether self-control typically reduces over time and why this decline may occur. The strength model of self-control (Baumeister, Vohs, \& Tice, 2007), which has also been termed the limited-resource model of self-control (Mead, Alquist, \& Baumeister, 2010) is included in discussions. This particular model has been reviewed in sport and exercise psychology previously (Englert, 2016; Hagger, Wood, Stiff, \& Chatzisarantis, 2010), hence, a broader perspective is adopted to shed light on alternative models that have evolved in recent years, including shifting priorities (Milyavskaya \& Inzlicht, 2018), opportunity costs (Kurzban, Duckworth, Kable, \& Meyers, 2013) and psychobiological models (Pageaux, Marcora, Rozand, \& Lepers, 2015). These models are then reconciled with motivation-based theories, including structural (Kruglanski et al., in press) and self-determination (Ryan \& Deci, 2017) perspectives. This integration allows us to derive new ideas on how to optimise endurance performance through adaptive self-control and motivation.

\section{Defining self-control}


Trait and state self-control have been associated with a wide range of adaptive behaviours across multiple life domains (e.g., Baumeister et al., 2007; de Ridder, LensveltMulders, Finkenauer, Stok, \& Baumeister, 2012). Nonetheless, there are unique facets of trait and state self-control that make it difficult to draw broad conclusions befitting both levels of analysis, hence, the two concepts should not be used interchangeably (Allom, Panetta, Mullan, \& Hagger, 2016). For instance, individuals reporting high trait self-control may be worse at using self-control on specific occasions because they are less practiced in avoiding temptation (Imhoff, Schmidt, \& Gerstenberg, 2013). Moreover, reported trait self-control has no association with responses on two commonly employed situational measures of behavioural self-control (Saunders, Milyavskaya, Etz, Randles, \& Inzlicht, 2018). In endurance activities, situational self-control is likely a more proximal influence on performance, compared to dispositional self-control. Hence, the sole focus of this text is situational self-control.

Self-control refers to 'the capacity to resist a temptation that is in conflict with a desired, long-term goal, in order to protect this valued goal' (Fishbach \& Woolley, 2018, p167). Thus, self-control requires three components: a desire, a higher order goal and conflict between the two (i.e., desire-goal conflict; Kotabe \& Hofmann, 2015). Individuals can experience conflict between two distal valued goals (e.g., a student-athlete deciding between an important training session and an exam revision tutorial) or two proximal desires (e.g., eat an unhealthy cake or consume an alcoholic drink after training), but it is only when a desire conflicts with a distal goal that the significant cognitive disruption associated with self-control occurs (Kotabe \& Hofmann, 2015). Colloquial definitions of self-control also imply a conflict between a temptation and a distal goal, rather than goal-goal or desire-desire conflicts. 
Evolutionary accounts describe how humans are necessarily motivated to avoid painful and effortful experiences (Kool, McGuire, Rosen, \& Botvinick, 2010; Mees \& Schmitt, 2008), therefore, this definition of self-control can be applied to sustained athletic performance, despite the empirical basis of this definition being rooted in mainstream psychology. The urge to relieve the multifaceted distress associated with endurance

107 performance, such as respiratory discomfort (Smoliga, Mohseni, Berwager, \& Hegedus, 108 2016), sensations associated with lactic acid accumulation (Rotto \& Kaufman, 1988) or thermal discomfort (Schlader, Simmons, Stannard \& Mündel, 2011), by lessening work effort represents an immediately satisfying proximal desire. The desire to exercise at intensities that

111 lead to positive, rather than negative, affect is considerable (Ekkekakis, Backhouse, Gray, \& 112 Lind, 2008). In contrast, producing optimal athletic performance represents the valued distal 113 goal.

Desire-goal conflict can be predicted by the relative strengths of the desire and the higher order goal, and the degree of incompatibility between the two (Kotabe \& Hofmann, 2015). For example, relieving perceptions of discomfort associated with intense aerobic

117 activity versus maintaining optimal performance are clearly incompatible. However, for most 118 athletes, pursuing a gold medal in an Olympic final would be a stronger higher order goal 119 compared to merely obtaining useful performance data in training. As such, the desire-goal conflict is likely to be lower in the former scenario than the latter. On the other hand, desire-

121 goal conflict would increase as the perceived distress associated with performance effort 122 increases. When the cost of maintaining performance is sufficiently great to override benefits 123 of persisting, maximal exertion is abandoned (Botvinick \& Braver, 2015). The size of this cost rises as the number and magnitude of the different systems recruited increases. Unfortunately for athletes, elite sport performance places more demands on the brain and associated systems than most other activities (Walsh, 2014). The costs associated with 
127

128

129

130

131

132

133

134

135

136

137

138

139

140

141

142

143

144

145

146

147 the temptation, resolve the conflict, and use the experience to inform subsequent protective

148 behaviour (Gray \& McNaughton, 2000; Lazarus 1993; Tooby, Cosmides, Sell, Lieberman, \&

149 Sznycer, 2008). For example, endurance athletes use a variety of self-regulatory strategies

150

151

maintenance of optimal performance are, therefore, enormous. In everyday life, the negative affect associated with the costs of resisting a temptation in favour of a valued goal would lead to negative reinforcement and motivation to avoid a similar state. Indeed, affective states during exercise are a significant influence on future engagement (Rhodes \& Kates, 2015). However, during endurance performance it is necessary for athletes to repeatedly override this motivational response to succeed.

Although the example of overcoming performance-related discomfort in favour of optimal performance is used throughout this text, any athletic scenario in which an immediate temptation is contrasted with a distal goal can be applied. For example, athletes who are tempted to accept performance enhancing substances, to miss training for a party, or to contravene nutritional advice, will all require self-control to maintain pursuit of the distal goal of successful and legal athletic performance.

Reflecting broad cybernetic principles in which a disturbance from a reference state is identified and an output function is subsequently initiated (Carver \& Scheier, 1982), two stages of successful self-control are proposed to exist (Fishbach \& Converse, 2010; Fishbach \& Woolley, 2018). The first involves the identification of a goal-desire conflict which activates the behavioural inhibition system to initiate a negative affective state (Kurzban et al., 2013). In endurance performance, this would be the realisation that the desire to relieve performance related discomfort is conflicting with optimal performance. Second, this experience galvanizes an individual to inhibit responses or modify behaviour to counteract during competition, such as relaxation, mindfulness, and disassociation to modify responses to exertion (Brick, MacIntyre, \& Campbell, 2015). The two stages are distinct and are 
152

153

154

155

156

157

158

159

160

161

162

163

164

165

166

167

168

169

170

171

172

173

174

175

176

regulated by different areas of the brain, namely the anterior cingulate cortex and dorsolateral prefrontal cortex, respectively (Botvinick, Braver, Barch, Carter, \& Cohen, 2001;

MacDonald, Cohen, Stenger, \& Carter, 2007). Although there is some debate (Fujita, 2011), these self-control processes are generally understood to occur consciously, as opposed to broader definitions of self-regulation which include both automatic and conscious processes (Baumeister et al., 2007; Milyavskaya \& Inzlicht, 2018).

Attempts to categorize different types of self-control have been undertaken, including a review of self-control measures which revealed four dimensions of self-control (Whiteside \& Lynam, 2001). Urgency is the inability to resist strong impulses, lack of premeditation refers to acting before thinking, lack of perseverance reflects the inability to attend to uninteresting or difficult tasks, and sensation seeking is a tendency towards exhilarating and risky activities. Psychometric and neuro-scientific evidence points to considerable conceptual overlap among the first three dimensions and they align with the definition of self-control provided. The same evidence points to sensation seeking representing a distinct phenomenon and is not considered in this text (Duckworth \& Kern, 2011; Steinberg, 2008).

\section{Does self-control diminish over time?}

There is an impressive weight of evidence to suggest that individuals do not reliably sustain self-control over time. This idea forms the basis of the strength model of self-control (Baumeister et al., 2007). The theory's major postulate is that, after initial acts of self-control, an individual's capacity to exert further self-control becomes diminished (Baumeister et al., 2007; Hagger et al., 2010). This attenuation of self-control resource has been termed 'egodepletion' by advocates of the strength model (Baumeister, Bratslavsky, Muraven, \& Tice, 1998) and replenishment of self-control occurs with rest (Tyler \& Burns, 2008). Evidence for the ego-depletion effect has typically employed a sequential-task paradigm consisting of an initial experimental task in which self-control exertion is manipulated, followed by an 
177 unrelated second task requiring self-control. A meta-analysis of 198 experiments reported

178 that, in conditions where self-control is needed during the first task (compared to no or

179 limited self-control required), self-control is diminished during the second task (Hagger et al.,

180 2010). Overcoming the urge to quit or reduce effort during prolonged or intense exercise

181 requires self-control; therefore, the sequential-task protocol has been employed in exercise

182 settings. Following a cognitive task requiring self-control to override response tendencies,

183 participants performed worse during indoor cycling and running tasks, compared to when

184 they completed a cognitively simple congruent Stroop task (Englert \& Wolff, 2015;

185 MacMahon, Schücker, Hagemann, \& Strauss, 2014; Pageaux, Lepers, Dietz, \& Marcora,

186 2014). Reduced cycling performance has also been induced when participants first watched

187 an upsetting video and were instructed to suppress their emotional responses (i.e., self-control

188 condition), compared to when participants were given no guidance regarding emotion

189 regulation (i.e., control condition; Wagstaff, 2014).

190 Despite popularity and support for this tenet of the strength model, it has encountered

191 major challenges. A meta-analysis using different study inclusion criteria to those of Hagger

192 and colleagues (2010) and additional statistical techniques to correct for small-study effects

193 led to the conclusion that 'self-control in general does not decrease as a function of previous

194 use' (Carter, Kofler, Forster, \& McCullough, 2015, p18). A multi-lab replication also failed

195 to evidence the hypothesized reduction in self-control (Hagger et al., 2016), which has led to

196 a series of commentaries, analyses, and debates (e.g., Baumeister \& Vohs, 2016; Dang, 2017;

197 Hagger \& Chatzisarantis, 2016; Sripada, Kessler, \& Jonides, 2016;). A further re-analysis

198 suggests that it may be too early to conclude whether the effect is an experimental or

199 statistical artefact (Blázquez, Botella, \& Suero, 2017).

200 In addition to the debate around the existence of self-control decline, numerous

201 studies have identified simple ways to sustain self-control, including incentives (Mischel \& 
202 Patterson, 1976; Muraven \& Slessareva, 2003), providing choice (Moller, Deci \& Ryan, 203 2006), watching an enjoyable TV show (Derrick, 2012), and meditating (Friese, Messner \&

204 Schaffner, 2012). Individuals' prior beliefs about self-control also attenuate self-control 205 reductions (Clarkson, Hirt, Jia, \& Alexander, 2010; Job, Dweck, \& Walton, 2010) and ego206 depletion effects may be culturally grounded (Savani \& Job, 2017). It is this fragility which 207 has made the ego-depletion effect so difficult to replicate, leading to the phenomenon 208 unwittingly taking centre stage in conversations about the 'replication crisis' in psychology 209 (Open Science Collaboration, 2015). It is, therefore, questionable whether any added value 210 would be gained from exploring the existence of the ego-depletion effect further. Instead, 211 embracing this instability and identifying the conditions leading to the ego-depletion 212 phenomenon to express itself is empirically valuable (see Iso-Ahola, 2017). For example, a 213 tipping-point of between four and six minutes of self-control exertion may be necessary for 214 reductions in self-control on a subsequent muscular endurance task to occur (Brown \& Bray; 215 2017). Further increases in initial self-control use did not lead to changes in magnitude of the 216 depletion effect. Alternatively, it has been suggested that typical self-control tasks may not be 217 prolonged enough to induce subjective feelings of mental fatigue (Pageaux, Marcora, \& 218 Lepers, 2013) and cognitive tasks lasting 30 minutes or longer have been suggested to induce 219 more reliable performance decrements on endurance tasks (Van Custem, Marcora, De Pauw, 220 Bailey, Meeusen, \& Roelands, 2017).

The beginning of this article outlined the importance of effective self-control for 222 successful performance. However, self-control decline and the considerable cognitive costs 223 associated with self-control attempts counterintuitively imply that athletes who rely on it for successful performance will likely fail. During self-control, increasing cognitive demand is a

225 signal that the value of the alternative temptation (e.g., relieving performance distress) is 226 beginning to outweigh the goal-oriented task (Kool et al., 2010). The more time spent 
exerting self-control, the greater the aversive experience (Kool \& Botvinick, 2014). Despite evolutionary benefits (see Kurzban et al., 2013) this consequence does not help athletes maintain maximal performance effort. Hence, we contend that forestalling self-control

230 processes can enhance endurance performance. In our example, the athlete is fighting the

231 urge to reduce painful experiences (e.g., dyspnoea, afferent signals from lactic acid

232 accumulation). However, psychophysiological sensations of pain may not necessarily

233 coincide with a negative affective state (Price, 2000). Only when the sensations associated

234 with increasing aerobic effort conflict with the goal of successful performance (i.e., a desire-

235 goal conflict exists) will negative affect occur and self-control be initiated.

236 To provide greater clarity, consider two endurance athletes. The first athlete values

237 successful performance but experiences trepidation of the amount of effort required and pain 238 to overcome. In this example, there is a desire (to avoid the pain), which conflicts with a goal 239 (successful performance). This desire-goal conflict initiates the self-control process, and the 240 costly and aversive experience of self-control begins to accumulate. A second athlete values

241 successful performance equally well, however, this athlete considers the performance-related 242 discomfort as an important and necessary element of goal pursuit. By fusing the activity of 243 overcoming discomfort with the goal of successful performance, the discomfort becomes 244 instrumental to the goal, not in conflict with it (c.f., Kruglanski et al., in press). Consequently, 245 initiation of self-control can be delayed, leading to decreased negative affect and cognitive 246 load, and subsequent enhanced endurance performance. Outside of sport, greater persistence 247 on a reading task occurred when the goal of a bonus payment was fused to the task, rather 248 than a distinct bonus and task or no payment control condition (Woolley \& Fishbach, 2016).

249 This implies that, although exerting self-control to overcome performance-related discomfort 250 will be necessary at some point for successful performance, delaying self-control exertion by 251 reducing the discomfort-performance conflict will enhance performance. In practical terms, 
252

253

254

255

256

257

258

259

260

261

262

263

264

265

266

267

268

269

270

271

272

273

274

275

276

perceiving the need to overcome performance-related discomfort as part of successful performance, rather than as an obstruction to it, should achieve this delay.

Even with a highly integrated process and goal, at some point, the desire to remove performance-related discomfort will conflict with successful performance and self-control will be required. During these assumed latter stages of endurance performance, we suggest that the focus should be on embracing this conflict, rather than supressing it. The degree to which the affective distress signal of a desire-goal conflict recruits self-control is moderated by the individual's acceptance of the distress (Inzlicht \& Legault, 2014; Kashdan \& Rottenberg, 2010). Without this aversive experience, goal conflicts would go unidentified and resolution could not take place (Inzlicht \& Legault, 2014). In sport, emotion is often viewed as counterproductive to performance (Lee Sinden, 2010, 2012). In contrast, self-control theorists propose that affective consequences of self-control are aversive, yet adaptive and necessary element of successful task performance (Inzlicht \& Legault, 2014). This response is the signal that things could go awry and there is a need to initiate self-control. Only by accepting the negative affect can one make appropriate decisions regarding behavioural, emotional or cognitive corrections. A lack of acceptance will lead to immediately gratifying defensive responses to the distress, which in the context of endurance performance is expected to be a reduction of effort. Moreover, the aversive state related to goal conflict releases nor-epinephrine, which is associated with heightened attention (Aston-Jones \& Cohen, 2005). The aversive state may, therefore, have some positive implications for performance contexts where psycho-physiological arousal is beneficial.

This hypothesis has applicability to sport psychology research, where a psychological skills training perspective advocates suppression of, rather than acceptance of, negative internal states (Gardner \& Moore, 2007). Doing so will lead to an inability to use affective information to motivate subsequent action (Inzlicht \& Legault, 2014). Instead, a mindful 

internal resource that is consumable but limited (Baumeister et al., 1998). Congruent with this

awareness and non-judgmental acceptance can amplify conflict-related affect and effectively mobilise self-control (Elkins-Brown, Teper, \& Inzlicht, 2017). Professional ballet dancers reported greater awareness of pain during a cold pressor test, compared to age matched controls, but were more effective in exerting self-control (Tajet-Foxell \& Rose, 1995). To achieve this performance state, it is necessary to devise strategies for the latter stages of endurance performance. Inzlicht and colleagues (2014) recommend focusing on monitoring, attending to, and acceptance of goal conflict through mindfulness training and implementation intention strategies. Mindfulness training empowers individuals to nonjudgementally attend to the present moment (Kabat-Zinn, 2003) and has gathered some momentum within sport psychology (e.g., Gardner \& Moore, 2012). This technique may be effective by nurturing acknowledgement and acceptance of the experiential affect that signals the need for self-control (Teper \& Inzlicht, 2013; Teper, Segal, \& Inzlicht, 2013). In addition, mindful individuals have a greater sensitivity to the need for self-control and can monitor goal conflict and self-control processes effectively (Elkins-Brown et al., 2017).

Implementation intention strategies are behavioural or cognitive plans in response to anticipated situations (Gollwitzer \& Oettingen, 2011). These plans likely improve self-control by reducing the discrepancy between behaviour and distal goal. Mindfulness interventions have shown promise in impacting upon athletic performance, but self-control has not been considered as a mechanism for these effects, and the research lacks methodological rigor (Sappington \& Longshore, 2015). Implementation intentions have not been studied in endurance performance contexts.

\section{Why does self-control fade?}

The strength model of self-control describes how self-control draws energy from an limited resource perspective, an argument exists that individuals are motivated to conserve 
self-control if future need is anticipated, which may be reflected in poorer self-control prior to the anticipated future use (Muraven, Shmueli, \& Burkley, 2006). However, the identification of the resource that is depleted remains elusive. Glucose has been suggested as a candidate resource and initial studies revealed that engaging in self-control reduced blood glucose, which in turn was associated with impaired performance on subsequent measures of self-control (Gailliot et al., 2007). In addition, imbibing a glucose-based drink has been shown to attenuate the ego-depletion effect (DeWall, Baumeister, Gailliot, \& Maner, 2008; Gailliot et al., 2007). However, both these effects have been inconsistently observed (Lange \& Eggert, 2014; Lange, Seer, Rapior, Rose, \& Eggert, 2014; Molden et al., 2012). In sport

311 research, reductions in endurance performance following mentally fatiguing tasks have been 312 shown to occur without reductions in blood glucose (Marcora, Staiano, \& Manning, 2009).

313 Critically, there is an assumption that equilibrium exists between glucose in the blood and the 314 brain (Lund-Anderson, 1979). However, changes in blood glucose resulting from cognitive 315 effort are unlikely to be caused by increased brain glucose uptake (Messier, 2004) and brain 316 activation consumes little additional glucose compared to enduring basal requirements 317 (Raichle \& Gusnard, 2002). Kurzban (2010) expands on these arguments to conclude that it is highly unlikely that glucose is the resource on which self-control is based on. Despite these metabolically-based refutations, glucose may still be associated with self-control processes in other ways. Mouth rinsing then spitting glucose-based drinks can 321 ameliorate self-control reductions without any enhanced blood glucose availability (Hagger 322 \& Chatzisarantis, 2013; Molden et al., 2012; Sanders, Shirk, Burgin, \& Martin, 2013). 323 Indeed, the perceptual effects of self-control use and glucose ingestion may be similar given that oral exposure to glucose activates similar areas of the brain (e.g., anterior cingulate cortex; Chambers, Bridge, \& Jones, 2009; Rolls, 2007) as the initiation of self-control 
327 Stroop task, ingestion of glucose, or a combination of both experimental manipulations led to 328 similar performance trends during 16 kilometre cycling time trials (Boat, Taylor, \& Hulston, 329 2017).

In sum, it is unlikely that glucose is the central resource behind self-control processes.

331 But ruling out one candidate resource does not preclude the existence of another. Certainly, a 332 global element to self-control exists given that the two tasks comprising the sequential-task 333 paradigm are often unrelated, thus demonstrating cross-contextual effects. This global 334 characteristic is most easily observed in sport performance research where the first task is a 335 cognitive function (e.g., resisting a natural response tendency) and the second is physical 336 (e.g., endurance performance task). Nonetheless, the search for a biological foundation of 337 self-control continues. Some theories acknowledge capacity-based explanations for selfcontrol failure, but usually these refer to the non-motivational cognitive resources (e.g., executive function) that help resist temptation in the pursuit of the distal goal (Kotabe \& 340 Hoffmann, 2015), rather than any biological resource. In contrast to the limited resource argument, several theories of self-control, effort,

342 and attention can be reconciled under the core hypothesis that reductions in self-control 343 performance can be accounted for by a shift in attentional and perceptual foci. The shifting 344 priorities model of self-control (Inzlicht \& Schmeichel, 2016; Milyavskaya \& Inzlicht, 2018) 345 describes how attentional processes resolve the self-control dilemma by shifting the salience 346 of the immediate temptation or the valued distal goal. In other words, initial self-control use 347 leads to a shift in focus towards the temptation, hence reduced self-control in a subsequent 348 task. Similarly, modifications in perception of effort have been proposed to be the central 349 mechanism explaining how mental fatigue reduces endurance performance (Pageaux et al., 350 2015). From a psychobiological perspective, mental fatigue stemming from prolonged 351 exertion of self-control induces neurochemical changes in the brain (e.g. adenosine 
accumulation in the anterior cingulate cortex) that result in an incremental shift in perception of effort required and, therefore, premature exhaustion during subsequent endurance performance (Marcora, 2008). Self-control depletion and mental fatigue similarly require consistent conscious effort that may stimulate negative feelings (Hagger et al., 2010), and both may lead to an unwillingness to employ further effort and performance decrements

357 (Inzlicht \& Schmiechel, 2012). Self-control and cognitive fatigue experiments typically vary 358 in the tasks that are utilised; mental fatigue tasks usually last considerably longer than the tasks that are employed in self-control depletion research. For example, 90 minute tasks have been used to induce cognitive fatigue (Marcora et al., 2009) whereas, tasks as short as four minutes have been employed to induce self-control exertion (Boat et al., 2017). It is important to note, however, that this distinction is based on the method to induce mental fatigue or self-control, not on the construct itself. Overall, reduced self-control and mental fatigue share much communality.

The attentional and perceptual shifts described above have a greater body of supportive evidence from sport research, compared to the limited resource argument. For instance, participants reported greater perceptions of pain and reduced persistence during a postural endurance task following self-control exertion, compared to when they did not initially exert self-control (Boat \& Taylor, 2017). The idea that increased awareness of somatic sensations can act as a motivational input eventually leading to the cessation of effort

371 has considerable overlap with Tenenbaum's (2001) social cognitive model of attentional

372 focus in sport. During high intensity exercise, athletes' attention is dominated by perceptions

373 of physiological effort and the ability to switch away from this experience is severely

374 diminished (Hutchinson \& Tenenbaum, 2007). Visual and aural attention also shifts

375 following self-control exertion, leading to reduced performance in dart throwing and 376 basketball free throws, especially in high pressure situations (Englert, Bertrams, Furley, \& 
377 Oudejans, 2015; Englert, Zwemmer, Bertrams, \& Oudejans, 2015). However, this attentional

378 shift was not replicated during a hypothetical basketball decision-making task (Furley,

379 Bertrams, Englert, \& Delphia, 2013).

Evidence founded on psychobiological models draws similar conclusions. Cognitive

381 fatigue tasks, including a 90 minute AX-Continuous Performance Task (Carter, Braver,

382 Barch, Botvinick, Noll, \& Cohen, 1998) and a 30 minute Stroop task, have been employed to

383 demonstrate that mental fatigue enhances perceptions of effort, which facilitates

384 disengagement during time-to-exhaustion endurance performance tasks (Pageaux et al., 2014;

385 Marcora et al., 2009). In these studies, there were negligible or no difference in heart rate

386 across conditions, suggesting that mental fatigue does not limit exercise tolerance through

387 cardiorespiratory mechanisms (Marcora et al., 2009; Van Custem et al., 2017). Overall, there

388 is strong theoretical and empirical evidence to suggest that shifting attentional focus is the

389 most plausible explanation for self-control reductions in sport contexts. Hence, it is necessary

390 to identify how attention can be shifted towards factors conducive to, rather than obstructive

391 of, self-control processes during endurance performance. In the following section, we argue

392 that a focus on motivation will help us achieve this goal.

Many theories of self-control describe motivational mechanisms to explain self-

control processes, including the shifting priorities model of self-control (Milyavskaya \&

Inzlicht, 2018) and the opportunity-costs model (Kurzban et al., 2013). The strength model of

396 self-control somewhat differs in this respect by proposing a non-motivational mechanism

397 explaining self-control failure, but even this theory suggests motivation can moderate

398 reductions in self-control (Baumeister, 2016; Baumeister \& Vohs, 2007). According to

399 motivational theories, the motivational basis behind the conflicting desire and goal influences

400 the attentional processes described above. In turn, attention can guide a subjective valuation

401 process in which distal and proximal choices are constantly evaluated (Berkman, Livingston, 
402 Kahn, \& Inzlicht, 2015) and individuals decide appropriate levels of task engagement based

403 on the prioritization of these choices (Kurzban et al., 2013). Motivational intensity theory

404 (Brehm \& Self, 1989; Gendolla \& Richter, 2010), the guiding framework shaping

405 psychobiological explanations of endurance performance (Marcora, 2008), also highlights the

406 conscious evaluation of required effort and task difficulty as a central decision in task

407 engagement (Wright et al., 2007; Wright, Stewart, \& Barnett, 2008). In other words, an

408 endurance athlete will continually evaluate the pros and cons of reducing or sustaining effort

409 to achieve success. For example, the increasing pain sensations during sustained, high

410 intensity performance can lead an athlete to progressively focus on relieving the pain

411 (attentional priorities shift; Hutchinson \& Tenenbaum, 2007), eventually weighing this goal

412 more heavily than the importance of winning. The dynamics between valued goals and

413 immediate gratification would have been adaptive for primordial ancestors (Beedie \& Lane,

414 2012; Kurzban et al., 2013). In particular, the opportunity-cost model has strong roots in

415 evolutionary psychology of foraging organisms. Put simply, an organism is required to

416 constantly evaluate the opportunity costs of foraging in the same patch versus changing

417 location (Gallistel, 1990). Recent literature from shifting-priority theorists is consistent with

418 this evolutionary account. When individuals exploit known rewards only, it prevents

419 exploration and potential identification of larger and more efficiently obtained rewards

420 (Inzlicht, Schmeichel, \& McRae, 2014).

421 There are myriad motivational inputs that can influence attention and decisional

422 processes, for example, most proximal temptations are instantly enjoyable or satisfying and

423 offer more certainty, relative to distal goals (Kahneman \& Tversky, 1979). The relationship

424 between motivation and effective self-regulation has been scrutinised for several decades.

425 Tenets of self-determination theory (Ryan \& Deci, 2017), a prevalent theory in sport and

426 exercise psychology research (see Taylor, 2015), offers several avenues for theoretical 
427

428

429

430

431

432

433

434

435

436

437

438

439

440

441

442

443

444

445

446

447

integration. This amalgamation can assist in deriving several mechanistic hypotheses explaining how motivation can enhance endurance performance. Broadly speaking, we contend that internalizing and integrating successful performance will facilitate self-control in several ways. According to self-determination theory, humans are fundamentally inclined towards growth, which partly expresses itself as a tendency to internalise extrinsically driven behaviour so that it becomes integrated with one's true sense of self (Ryan \& Deci, 2017). Internalised goals and motives are autonomous, freely chosen, of personal meaning, and concordant with one's true sense of self. In contrast, motives and goals that have not been internalised are deemed to be controlling, extrinsic in nature and point towards receiving rewards or avoiding punishment (Kasser \& Ryan, 1996; Ryan \& Deci, 2017).

Conflict-based self-control failures typically occur if the temptation or desire becomes too strong (Kotabe \& Hoffman, 2015) but this failure can be avoided if successful endurance performance is internalised and autonomously driven. In a series of studies, autonomous motivation was associated with decreased attraction to proximal temptations (Milyavskaya, Inzlicht, Hope, \& Koestner, 2015). This finding explains why autonomous goals are easier to pursue (Werner, Milyavskaya, Foxen-Craft, \& Koestner, 2016) and are less fatiguing (Moller et al., 2006; Muraven, 2008), relative to controlling goals. In other words, autonomously motivated individuals do not rely on greater self-control to resist temptations; they perceive temptations as less prominent, which make goal progress smoother. This hypothesis implies that autonomously motivated athletes will see performance-related discomfort as a less salient barrier to successful performance, relative to athletes energized by controlling motivations. Over time, this process is more likely to become habit in autonomously motivated individuals (Radel, Pelletier, Pjevac, \& Cheval, 2017).

In addition to reducing the prominence of temptations, autonomous motivation acts as a motivational input to increase the salient of the long-term goal (i.e., enhanced endurance 
performance) preventing a shift in priority to the proximal temptation (Berkman et al., 2015).

453 Goals that are central to one's self-description are more chronically and easily activated when

454 the context requires it, relative to goals held distant from the self (Higgins, 1996; Markus,

455 1977). This ease of activation holds considerable influence over attentional and evaluative

456 processes (Ferguson \& Bargh, 2004; Milyavskaya et al., 2015) and, therefore, can protect the

457 goal from competing temptations (Fishbach \& Shah, 2006). As such, autonomously

458 motivated athletes who wholly identify with successful performance should not only perceive

459 the temptation to reduce effort as less salient, but also psychologically approach and dedicate

460 appropriate cognitive resources towards the valued goal of successful performance

461 (Ntoumanis et al., 2014).

462

The third explanation concerning why autonomous motivation can enhance endurance

463

performance reflects the tendency to recover from an error or setback. The constant effort

464

required to override aversive feelings associated with endurance performance means

465

occasional slips in self-regulation are unavoidable. Trait and situational autonomy leads to

466 greater sensitivity and responsiveness to these errors, which, in turn leads to superior self-

467 regulatory performance (Legault, \& Inzlicht, 2013). In addition, appraisal of self-regulatory

468 strategies can occur following performances. Autonomously motivated individuals embrace

469 information that is relevant to the self and can acknowledge and accept personal deficiencies,

470 in comparison to individuals driven by controlling motives who perceive a greater threat

471 response (Hodgins, 2008; Hodgins \& Knee, 2002; Weinstein, Deci, \& Ryan, 2011). By

472 reflecting on barriers to optimal performance, autonomously motivated individuals can plan

473 strategies and responses that promote distal goal accomplishment. Specifically, autonomously

474 oriented individuals create if-then plans that specify when, where, and how people will

475 instigate responses if the goal is threatened (Carraro \& Gaudreau, 2011). To this end,

476 autonomously motivated athletes should be able to identify, accept and rectify self-regulatory 
477 errors, such as momentary lapses in optimal effort within a single performance context.

478 Moreover, autonomously motivated athletes are likely to reflect on self-regulation following

479 performances and create effective plans to override the temptation of relieving performance-

480 related discomfort when it occurs in the future. Both intra- and inter-performance processes

481 should yield better endurance performance.

482 Overall, this integration of self-determination theory and models of self-control

483 suggests that when performance is integrated with one's true sense of self (i.e., an

484

autonomous goal) the greater likelihood of optimal performance because a) the temptation to

485

reduce effort is less salient, b) the goal of optimal performance is attended to more

486 effectively, and c) self-regulatory errors are embraced and rectified more efficiently. It is

487 worth noting that this list of explanations may not be complete and there may be other

488 reasons why motivation influences self-control and subsequent athletic performance. For

489

example, controlled motivation, relative to autonomous motivation might lead to a greater

490

physiological stress response (Reeve \& Tseng, 2011). This stress response may lead to

491 decreased self-regulatory performance due to decreased executive function (Starcke, Wiesen,

492 Trotzke, \& Brand, 2016). Alternatively, enhanced cortisol response may initiate more

493 effective metabolic responses to exercise demands (Coker \& Kjaer, 2005).

\section{Summary and final thoughts}

By reviewing several prominent ideas behind self-control, we have attempted to

496 widen the theoretical scope of this important research topic. Collective consideration of the

497 various models will allow a broader depth of knowledge to develop in the race to improve

498 athletic performance. This is not to dismiss the idea of singular theoretical explanations, but

499 to shed light on complementary hypotheses, establish greater theoretical depth, and

500 encourage sport researchers to be at the forefront of research progress. One of the strongest

501 elements of the self-control literature is that it is almost entirely based on experimental 
502 designs with random samples that point strongly to causal effects. Moreover, the dependent 503 variables are almost always behavioural (e.g., giving up on a task, responding slower to a

504 stimulus), as opposed to self-report variables common in sport psychology work. As such, 505 evidence contained within the self-control literature would almost entirely be categorised as 506 high quality.

507 Within the article we propose several extensions to current knowledge. These 508 proposals are based on the integration of self-control and motivational theory. First, we 509 integrate self-control definitions and structural motivational perspectives (Kruglanski et al., in 510 press) to hypothesise that a fusion of the process of overcoming performance-related

511 discomfort and performance goals will reduce the desire-goal conflict required for initiation

512 of self-control. This fusion will delay aversive and costly consequences that may impede

513 performance. This idea is followed by the suggestion that attentional processes, rather than

514 limited resources explain why self-control reduces over time, yet we also highlight that

515 glucose remains an interesting construct to study in self-control research, but not as a

516 resource that self-control is based upon. The final section is based on a mutual consideration

517 of several self-control theories that place motivation as a central mechanism and self-

518 determination theory. By focusing on autonomous goals and motivation as a key motivational 519 input in the self-control process, we can speculate on three mechanistic explanations of how 520 to improve self-control. Autonomous regulation during endurance performance can a) reduce 521 the salience of the desire to reduce performance-related discomfort, b) increase the attentional 522 resources dedicated to optimal performance goals, and c) help monitor and modify self523 control more effectively during performance and over time.

524 Examination of the ideas proposed can provide greater understanding of the 525 psychological processes before and during athletic performance, as well as greater theoretical 526 insight into the conditions required for self-control maintenance. It is a simple suggestion that 
527 self-control and motivation research might dovetail well and provide new insight. However,

528 realizing these types of investigation requires collaboration across scientific fields as the

529 theories are couched in different scientific philosophies. The opportunity-cost model, for

530 example, embeds motivation within information-processing paradigms representing

531 fundamental computational decisions (e.g., Kurzban et al., 2013). In contrast, sport

532 psychologists with knowledge of self-determination theory generally conceptualize

533 motivation within broader phenomenological perspectives focusing on the sense of self (Ryan

$534 \&$ Deci, 2006).

535

Despite a history of self-regulation training within sport psychology (e.g., Hardy \&

536 Nelson, 1988), there are surprisingly few field interventions or basic experiments that have

537 attempted to improve self-control in sport, particularly those that focus on behavioural

538 measures, rather than self-report. As alluded to at the beginning of this article, this distinction

539 is important because self-report and behavioural measures evaluate discrete facets of self-

540 control that should not be viewed as equivalent (Allom et al., 2016; Imhoff, Schmidt, \&

541 Gerstenberg, 2013). Self-control training protocols have been examined extensively in non-

542 sport literature and shown to be somewhat effective but poorly understood (e.g., Friese,

543 Frankenbach, Job, \& Loschelder, 2017). Many of these training protocols, such as repeatedly

544 squeezing a handgrip or using one's non-dominant hand for everyday tasks over several

545 weeks, seem to lack the ecological validity necessary to transfer into sport training contexts.

546 On the one hand this gap represents a worrying lack of knowledge, but on the other, it

547 represents a ripe opportunity for exploration and advancement.

548 We have deliberately placed this article at the interface of mainstream psychology and

549 sport performance research. For instance, considerable evidence has accumulated from sport

550 researchers demonstrating attentional (e.g., Boat \& Taylor, 2017; Englert et al., 2015) and

551 perceptual shifts (Pageaux et al., 2014; Marcora et al., 2009) following self-control exertion, 
552 as well as the self-control control fade more generally (MacMahon et al., 2014; Wagstaff,

553 2014). In contrast, little sport research has established moderators and boundary conditions of

554 self-control reductions or the affective costs associated with self-control. Some of the

555 hypotheses we have put forward are also based on mainstream psychology, rather than sport-

556 specific research. For example, the idea that fusing processes and performance goals will

557 delay the desire-goal conflict and improve endurance performance has not been empirically

558 tested, nor has the mechanisms explaining why autonomous motivation enhances self-control

559 during endurance performance. We acknowledge and embrace this fact, and in doing so, we

560 align with arguments put forward by scholarly bodies to progress motivation science (see

561 open letter from the Society for the Science of Motivation here

562 http://www.thessm.org/MotivationalManifesto.pdf). In brief, we aim to progress from

563 establishing sport-specific motivational phenomena addressing specific applied problems, to

564 general motivational rules or principles that that lie beyond surface expressions in sport.

565

566

567

568

569

570

571

572

573

574

575

576 


\section{References}

578 Allom, V., Panetta, G., Mullan, B., \& Hagger, M. (2016). Self-report and behavioural

579

580

581

582

583

584

585

586

587

588

589

590

591

592

593

594

595

596

597

598

599

600

601 approaches to the measurement of self-control: Are we assessing the same construct? Personality and Individual Differences. 90, 137-142. doi:http://doi.org/10.1016/j.paid.2015.10.051

Ashton-Jones, G., \& Cohen, J. D. (2005). An intergrative theory of locus coeruleus norepinephrine function: Adaptive gain and optimal performance. Annual Review of Neuroscience, 28, 403-450. doi:10.1146/annurev.neuro.28.061604.135709

Baumeister, R. F. (2016). Limited Resources for Self-Regulation: A Current Overview of the Strength Model. Self-Regulation and Ego Control, 1-17

Baumeister, R. F., Bratslavsky, E., Muraven, M., \& Tice, D. M. (1998). Ego depletion: Is the active self a limited resource? Journal of Personality and Social Psychology, 74, 1252-1265. doi:http://dx.doi.org/10.1037/0022-3514.74.5.1252

Baumeister, R. F., \& Vohs, K. D. (2007). Self-regulation, ego depletion, and motivation. Social and Personality Psychology Compass, 1, 115-128. doi:10.1111/j.17519004.2007.00001.x

Baumeister R. F., \& Vohs K. D. (2016). Misguided effort with elusive implications. Perspectives on Psychological Science, 11, 574-575. doi:10.1177/1745691616652878

Baumeister, R. F., Vohs, K. D., \& Tice, D. M. (2007). The strength model of self-control. Current Directions in Psychological Science, 16, 351-355. doi:10.1111/j.1467-8721.2007.00534

Beedie, C. J., \& Lane, A. M. (2012). The role of glucose in self-control: Another look at the evidence and an alternative conceptualization. Personality and Social Psychology Review, 16, 143-153. 
602 Berkman, E., Livingston, J. L., Kahn, L. E., \& Inzlicht, M. (September 25, 2015) Valuation

603 as a Mechanism of Self-Control. Available at SSRN:http://ssrn.com/abstract=2665823

604 Blázquez, D., Botella, J., \& Suero, M. (2017). The debate on the ego-depletion effect:

605 Evidence from a meta-analysis with the p-uniform method. Frontiers in Psychology,

606 8, 197. doi:10.3389/fpsyg.2017.00197

607

Boat, R., \& Taylor, I. M. (2017). Prior self-control exertion and perceptions of pain during a 608 physically demanding task. Psychology of Sport \& Exercise, 33, 1-6.

609

Boat, R., Taylor, I. M., \& Hulston, C. J. (2017). Self-control exertion and glucose

610

611 supplementation prior to endurance performance. Psychology of Sport and Exercise, 29, 103-110. doi:http://dx.doi.org/10.1016/j.psychsport.2016.12.007

612 Botvinick, M., \& Braver, T. (2015). Motivation and cognitive control: From behaviour to 613 neural mechanism. Annual Review of Psychology, 66, 83-113.

614 doi:10.1146/annurev-psych-010814-015044

615 Botvinick, M. M., Braver, T. S., Barch, D. M., Carter, C. S., \& Cohen, J. C. (2001). Conflict 616 monitoring and cognitive control. Psychological Review, 108, 624-652. doi:http://dx.doi.org/10.1037/0033-295X.108.3.624

618 Brehm, J. W., \& Self, E. A. (1989). The intensity of motivation. Annual Review of 619 Psychology, 40, 109-131. doi:10.1146/annurev.psych.40.1.109

620 Brick, N., MacIntyre, T., \& Campbell, M. (2015). Metacognitive processes in the self621 622 regulation of performance in elite endurance runners. Psychology of Sport \& Exercise, 19, 1-9. doi:10.1016/j.psychsport.2015.02.003.

623

Brown, D. M. Y., \& Bray, S. R. (2017). Graded increases in cognitive control exertion reveal 624 a threshold effect on subsequent physical performance. Sport, Exercise, and Performance Psychology, 6, 355-369. http://dx.doi.org/10.1037/spy0000091 
626 Carraro, N. \& Gaudreau, P. (2011). Implementation planning as a pathway between goal

627

628

629

630

631

632

633

634

635

636

637

638

639

640

641

642

643

644

645

646

647

648

649

650 motivation and goal progress for academic and physical activity goals. Journal of Applied Social Psychology, 41, 1835-1856. doi:10.1111/j.1559-1816.2011.00795.x

Carter, C. S., Braver, T. S., Barch, D. M., Botvinick, N. M., Noll, D., \& Cohen, J. D. (1998). Anterior cingulate cortex, error detection, and the online monitoring of performance. Science, 280, 747-749. doi:10.1126/science.280.5364.747

Carter, E. C., Kofler, L. M., Forster, D. E., \& McCullough, M. E. (2015). A series of metaanalytic tests of the depletion effect: Self-control does not seem to rely on a limited resource. Journal of Experimental Psychology: General, 144, 796-815. doi:http://dx.doi.org/10.1037/xge0000083

Carver, C. S. \& Scheier, M. F. (1982). Control theory: A useful conceptual framework for personality-social, clinical and health psychology. Psychological Bulletin, 92, 111135. doi: 10.1037/0033-2909.92.1.111

Chambers, E. S., Bridge, M. W., \& Jones, D. A. (2009). Carbohydrate sensing in the human mouth: effects on exercise performance and brain activity. Journal of Physiology, 587, 1779-1994.

Clarkson, J. J., Hirt, E. R., Jia, L., \& Alexander, M. B. (2010). When perception is more than reality: The effects of perceived versus actual resource depletion on self-regulatory behaviour. Journal of Personality and Social Psychology, 98, 29-46. doi:10.1037/a0017539

Coker, R. H., \& Kjaer, M. (2005). Glucoregulation during exercise: The role of the neuroendocrine system. Sports Medicine, 35: 575-583. doi:0112-1642/05/0007-0575/\$34.95/0

Dang, J. (2017). An updated meta-analysis of the ego depletion effect. Psychological Research. Advance online publication. doi: 10.1007/s00426-017-0862-x 
651 de Ridder, D. T. D., Lensvelt-Mulders, G., Finkenauer, C., Stok, F. M., \& Baumeister, R. F. (2012). Taking stock of self-control: A meta-analysis of how trait self-control relates to a wide range of behaviors. Personality and Social Psychology Review, 16, 76-99. doi: $10.1177 / 1088868311418749$ doi:10.1177/0146167208323981

Duckworth A. L., \& Kern M. L. (2011). A meta-analysis of the convergent validity of selfcontrol measures. Journal of Research in Personality, 45, 259-268.

665 Ekkekakis, P., Backhouse, S. H., Gray, C., \& Lind, E. (2008). Walking is popular among 666 adults but is it pleasant? A framework for clarifying the link between walking and affect as illustrated in two studies. Psychology of Sport and Exercise, 9, 246-264.

Elkins-Brown, N, Teper, R., \& Inzlicht, M. (2017). How mindfulness enhances selfcontrol. In J. C. Karremans \& E. K. Papies (Eds.), Mindfulness in social psychology. New York, NY: Psychology Press.

Englert, C. (2016). The strength model of self-control in sport and exercise psychology. Frontiers in Psychology, 7, 314, doi:10.3389/fpsyg.2016.00314 with increased distractibility? Results from a basketball free throw task. Psychology of Sport and Exercise, 18, 26-31. doi:10.1016/j.psychsport.2014.12.001 
676 Englert, C., \& Wolff, W. (2015). Ego depletion and persistent performance in a cycling task. International Journal of Sport Psychology, 46, 137-151.

678 Englert C., Zwemmer K., Bertrams A., \& Oudejans R. R. D. (2015). Ego depletion and

679

680

681

682

683

684

685

686

687

688

689

690

691

692

693

694

695

696

697

698

699 attention regulation under pressure: Is a temporary loss of self-control strength indeed related to impaired attention regulation? Journal of Sport and Exercise Psychology, 37, 127-137. doi:10.1123/jsep.2014-0219

Ferguson, M. J. \& Bargh, J. A. (2004). How social perception can automatically influence behaviour. Trends in Cognitive Science, 8, 33-39.

Fishbach, A., \& Converse, B. A. (2010). Identifying and battling temptation. In K. D. Vohs \& R. F. Baumeister (Eds.), Handbook of self-regulation: Research, theory and applications (2nd edition; pp. 244-260). New York, NY: Guilford.

Fishbach, A., \& Shen, L. (2014). The explicit and implicit ways of overcoming temptation. In J. W. Sherman, B. Gawronski, \& Y. Trope (Eds), Dual process theories of the social mind (pp. 454-467). New York, NY: Guilford.

Fishbach, A., \& Woolley, K. (2018). Combatting temptation to promote health and wellbeing. In D. de Ridder, M. Adriaanse, \& K. Fujita (Eds.), Routledge International Handbook of self-control in health and well-Being (pp. 167-179). New York, NY: Routledge.

Friese, M., Messner, C., \& Schaffner, Y. (2012). Mindfulness meditation counteracts selfcontrol depletion. Consciousness and Cognition, 21, 1016-1022. doi:10.1037/0022-3514.91.3.456

Friese, M., Frankenbach, J., Job, V., \& Loschelder, D. (2017). Does self- control training improve self- control? A meta- analysis. Perspectives on Psychological Science, 12, 1077-1099. doi: 10.1177/1745691617697076. 
700 Fujita, K. (2011). On conceptualizing self-control as more than the effortful inhibition of

701

702

703

704

705

706

707

708

709

710

711

712

713

714

715

716

717

718

719

720

721

722

723 impulses. Personality and Social Psychology Review, 15, 352-66.

Furley, P., Bertrams, A., Englert, C., \& Delphia A. (2013). Ego depletion, attentional control, and decision making in sport. Psychology of Sport and Exercise, 14, 900-904. doi:http://dx.doi.org/10.1016/j.psychsport.2013.08.006

Gailliot, M. T., Baumeister, R. F., DeWall, C. N., Maner, J. K., Plant, E. A., Tice, D. M., ... Schmeichel, B. J. (2007). Self-control relies on glucose as a limited energy resource: Willpower is more than a metaphor. Journal of Personality and Social Psychology, 92, 325-336. doi:10.1037/0022-3514.92.2.325

Gallistel, C. R. (1990). The organization of learning. Cambridge, MA: Bradford Books: MIT Press.

Gardner, F. L., \& Moore, Z. E. (2007). The psychology of enhancing human performance: The Mindfulness-Acceptance-Commitment (MAC) approach. New York, NY: Springer Publishing.

Gardner, F. L., \& Moore, Z. E. (2012). Mindfulness and acceptance models in sport psychology: A decade of basic and applied scientific advancements. Canadian Psychology, 53, 309-318. doi: http://dx.doi.org/10.1037/a0030220

Gendolla, G. H. E., \& Richter, M. (2010). Effort mobilization when the self is involved: some lessons from the cardiovascular system. Review of General Psychology, 14, 212-226. doi:10.1037/a0019742

Gollwitzer, P. M., \& Oettingen, G. (2011). Planning promotes goal striving. In K. D. Vohs \& R. F. Baumeister (Eds.), Handbook of self-regulation: Research, theory, and applications (2nd edition, pp. 162-185). New York, NY: Guilford.

Gray, J. A., \& McNaughton, N. (2000). The neuropsychology of anxiety: An enquiry into the 
725

726

727

728

729

730

731

732

733

734

735

736

737

738

739

740

741

742

743

744

745

746

747

748 functions of the septo-hippocampal system ( $2^{\text {nd }}$ ed.). Oxford, UK: Oxford University Press.

Hagger, M. S., \& Chatzisarantis, N. L. D. (2013). The sweet taste of success: The presence of glucose in the oral cavity moderates the depletion of self-control resources. Personality and Social Psychology Bulletin, 39, 27-41. doi: $10.1177 / 0146167212459912$

Hagger, M. S., and Chatzisarantis, N. L. (2016). Commentary: Misguided effort with elusive implications, and sifting signal from noise with replication science. Frontiers in Psychology, 7:621. doi: 10.3389/fpsyg.2016.00621

Hagger, M. S., Chatzisarantis, N. L. D., Alberts, H., Anggono, C. O., Batailler, C., Birt, A., ... Zwienenberg, M. (2016). A multi-lab pre-registered replication of the egodepletion effect. Perspectives on Psychological Science, 11, 546-573. doi:10.1177/1745691616652873

Hagger, M. S., Wood, C., Stiff, C., \& Chatzisarantis, N. L. D. (2010). Ego depletion and the strength model of self-control: A meta-analysis. Psychology Bulletin, 136, 495-525. doi:10.1037/a0019486

Hardy, L., \& Nelson, D. (1988). Self-control training in sport and work. Ergonomics, 31, 1573-1585. doi:http://dx.doi.org/10.1080/00140138808966807

Higgins, E. T. (1996). Knowledge activation: Accessibility, applicability, and salience. In E. T. Higgins and A. W. Kruglanski (Eds.), Social psychology: Handbook of basic principles (pp. 133-168). New York: Guilford.

Hockey, G. R. J. (2011). A motivational control theory of cognitive fatigue. In P. L. Ackerman (Ed.), Cognitive fatigue: Multidisciplinary perspectives on current research and future applications (pp. 167-187). Washington, DC: American Psychological Association 
749 Hodgins, H. S. (2008). Motivation, threshold for threat, and quieting the ego. In H. A.

750

751

752

753

754

755

756

757

758

759

760

761

762

763

764

765

766

767

768

769

770

771

772 Wayment \& J. J. Bauer (Eds), Transcending self-interest: Psychological explorations of the quiet ego (pp. 117-124). Washington, WA: American Psychological Association.

Hodgins, H. S., \& Knee, C. R. (2002). The integrating self and conscious experience. In E. L. Deci \& R. M. Ryan (Eds.), Handbook of self-determination research (pp. 87-100). Rochester, NY: University Of Rochester Press.

Hutchinson, J. C., \& Tenenbaum, G. (2007). Attention focus during physical effort: The mediating role of task intensity. Psychology of Sport and Exercise, 8, 233-245. http://dx.doi.org/10.1016/j.psychsport.2006.03.006

Imhoff, R., Schmidt, A. F., \& Gerstenberg, F. (2013). Exploring the interplay of trait selfcontrol and ego depletion: Empirical evidence for ironic effects. European Journal of Personality, 28, 413-424. doi:10.1002/per.1899

Inzlicht, M., \& Legault, L. (2014). No pain, no gain: How distress underlies effective selfcontrol (and unites diverse social psychological phenomena). In J. Forgas \& E. Harmon-Jones (Eds.), The control within: Motivation and its regulation (pp. 115132). New York, NY: Psychology Press.

Inzlicht, M., Legault, L., \& Teper, R. (2014). Exploring the mechanisms of self-control improvement. Current Directions in Psychological Science, 23, 302-307. doi:10.1177/0963721414534256

Inzlicht, M., \& Schmeichel, B. J. (2012). What is ego depletion? Toward a mechanistic revision of the resource model of self-control. Perspectives on Psychological Science, 7, 450-463. doi:10.1177/1745691612454134

Inzlicht, M., \& Schmeichel, B. J. (2016). Beyond limited resources: Self-control failure as 
773

774

775

776

777

778

779

780

781

782

783

784

785

786

787

788

789

790

791

792

793

794

795

796

797 the product of shifting priorities. In K. Vohs \& R. Baumeister (Eds.), Handbook of Self-Regulation ( $3^{\text {rd }}$ edition, pp. 165-181). New York, NY: Guilford Press.

Inzlicht, M., Schmeichel, B. J., \& Macrae, C. N. (2014). Why self-control seems (but may not be) limited. Trends in Cognitive Sciences, 18, 127-133.

Iso-Ahola, S. E. (2017). Reproducibility in psychological science: When do psychological phenomena exist? Frontiers in Psychology, 8:879. doi: 10.3389/fpsyg.2017.00879

Job, V., Dweck, C. S., \& Walton, G. M. (2010). Ego depletion - is it all in your head? Implicit theories about willpower affect self-regulation. Psychological Science, 21, 1686-1693. doi:10.1177/0956797610384745

Kabat-Zinn, J. (2003). Mindfulness-based interventions in context: Past, present, and future. Clinical Psychology: Science and Practice, 10, 144-156. doi:10.1093/clipsy.bpg016

Kahneman, D., \& Tversky, A. (1979). Prospect theory: An analysis of decision under risk. Econometrica, 47, 263-292.

Kashdan, T. B., \& Rottenberg, J. (2010). Psychological flexibility as a function of health. Clinical Psychology Review, 30, 865-878. doi:10.1016/j.cpr.2010.03.001

Kasser, T., \& Ryan, R. M. (1996). Further examining the American dream: Differential correlates of intrinsic and extrinsic goals. Personality and Social Psychology Bulletin, $22,280-287$.

Kool, W., \& Botvinick, M. (2014). A labour/leisure trade off in cognitive control. Journal of Experimental Psychology. General, 143, 131-41. doi:10.1037/a0031048

Kool, W., McGuire, J. T., Rosen, Z. B. \& Botvinick, M. M. (2010). Decision making and the avoidance of cognitive demand. Journal of Experimental Psychology: General 139, 665-82. doi:10.1037/a0020198.

Kotabe, H. P., \& Hofmann, W. (2015). On integrating the components of self-control. 
818 Lee Sinden, J. (2012). The sociology of emotion in elite sport: Examining the role of 819

Perspectives on Psychological Science, 10, 618-638. doi:https://doi.org/10.1177/1745691615593382

Kruglanski, A. W., Fishbach, A., Woolley, K., Bélanger, J. J., Chernikova, N., Molinario, E., \& Pierro, A. (in press). A structural model of intrinsic motivation: On the psychology of means-ends fusion. Psychological Review.

Kurzban, R. (2010). Does the brain consume additional glucose during self-control tasks? Evolutionary Psychology, 2, 244-259.

Kurzban, R., Duckworth, A., Kable, J. W., \& Myers, J. (2013). An opportunity cost model of subjective effort and task performance. Behavioural and Brain Sciences, 36, 661-669. doi:10.1017/S0140525X12003196

Lange, F., \& Eggert, C. (2014). Sweet delusion. Glucose drinks fail to counteract ego depletion. Appetite, 75, 54-63. doi:10.1016/j.appet.2013.12.020

Lange, F., Seer, C., Rapior, M., Rose, J., \& Eggert, C. (2014). Turn it all you want: Still no effect of sugar consumption on ego depletion. Journal of European Psychology Students, 5, 1-8. doi:10.5334/jeps.cc

Lazarus, R. S. (1993). From psychological stress to the emotions: A history of changing outlooks. Annual Review of Psychology, 44, 1-21.

Lee Sinden, J. (2010). The normalization of emotion and the disregard of health problems in elite amateur sport. Journal of Clinical Sport Psychology, 4, 241-256. doi:10.1123/jcsp.4.3.241 normalization and technologies. International Review for the Sociology of Sport, 48, 613-628. doi:10.1177/1012690212445274.

Legault, L., \& Inzlicht, M. (2013). Self-determination, self-regulation, and the brain: 
Autonomy improves performance by enhancing neuroaffective responsiveness to self-

823 regulation failure. Journal of Personality and Social Psychology, 105, 123-138.

824 doi:10.1037/a0030426

825

Lund-Anderson, H. (1979). Transport of glucose from blood to brain. Physiological Review,

826 $59,305-352$.

827

MacDonald. A. W., Cohen, J. D., Stenger, V. A., \& Carter, C. S. (2007). Dissociating the role 828 of the dorsolateral prefrontal and anterior cingulate cortex in cognitive control.

829 Science, 288, 1835-1838.

830

MacMahon, C., Schücker, L., Hagemann, N., \& Strauss, B. (2014). Cognitive fatigue effects

831

832 on physical performance during running. Journal of Sport and Exercise Psychology, 36, 375-381. doi:10.1123/jsep.2013-0249

Marcora, S. M. (2008). Do we really need a central governor to explain brain regulation of 834 exercise performance? European Journal of Applied Physiology, 104, 929-931.

835 doi:10.1007/s00421-008-0818-3

836 Marcora, S. M., Staiano, W., \& Manning, V. (2009). Mental fatigue impairs physical 837

838 performance in humans. Journal of Applied Physiology, 106, 857-864.

839

Martin, K., Staiano, W., Menaspà, P., Hennessey, T., Marcora, S., Keegan, R., . . Rattray, B.

840 (2016). Superior inhibitory control and resistance to mental fatigue in professional road cyclists. PLoS ONE, 11, e0159907. doi:10.1371/journal.pone.0159907

842 Markus. H. (1977). Self-schemata and processing information about the self. Journal of $843 \quad$ Personality and Social Psychology, 35, 63-78.

844 Mead, N. L., Alquist, J. L., \& Baumeister, R. F. (2010). Ego depletion and the limited 
845

846

847

848

849

850

851

852

853

854

855

856

857

858

859

860

861

862

863

864

865

866

867

868

869

resource model of self-control. In R. R. Hassin, K. N. Ochsner, \& Y. Trope (Eds.), Self-control in society, mind, and brain (pp. 375-388). New York, NY: Oxford University Press. doi:10.1093/acprof:oso/9780195391381.003.0020

Mees, U., \& Schmitt, A.(2008). Goals of action and emotional reasons for action: A modern version of the theory of ultimate psychological hedonism. Journal for the Theory of Social Behavior. 38, 157-178. doi:10.1111/j.1468-5914.2008.00364.x

Messier, C. (2004). Glucose improvement of memory: A review. European Journal of Pharmacology, 19, 33-57. doi:0.1016/j.ejphar.2004.02.043

Milyavskaya, M., \& Inzlicht, M. (2018). Attentional and motivational mechanisms in selfcontrol. In D. de Ridder, M. Adriaanse, \& K. Fujita (Eds.), Handbook of self-control in health and well-Being (pp.11-23). New York, NY: Routledge.

Milyavskaya, M., Inzlicht, M., Hope, N. \& Koestner, R. (2015). Saying 'No' to temptation: 'Want-to' motivation improves self-regulation by reducing temptation rather than by increasing self-control. Journal of Personality and Social Psychology, 109, 677-693. doi: $10.1037 / \mathrm{pspp} 0000045$

Mischel, W. \& Patterson, C. J. (1976). Substantive and structural elements of effective plans for self-control. Journal of Personality and Social Psychology, 34, 942-950

Molden, D. C., Hui, C. M., Scholer, A. A., Meier, B. P., Noreen, E. E., D’Agostino, P. R., \& Martin, V. (2012). Motivational versus metabolic effects of carbohydrates on selfcontrol. Psychological Science, 23, 1137-1144. doi:10.1177/0956797612439069

Moller, A. C., Deci, E. L., \& Ryan, R. M. (2006). Choice and ego-depletion: The moderating role of autonomy. Personality and Social Psychology Bulletin, 32, 1024-1036. doi:10.1177/0146167206288008

Muraven, M. (2008). Prejudice as self-control failure. Journal of Applied Social Psychology, 38, 314-333. doi:10.1111/j.1559-1816.2007.00307.x 
870 Muraven, M., Shmueli, D., \& Burkley, E. (2006). Conserving self-control strength.

871

872

873

874

875

876

877

878

879

880

881

882

883

884

885

886

887

888

889

890

891

892 Personality Processes and Individual Differences, 91, 524-537. doi:http://dx.doi.org/10.1037/0022-3514.91.3.524

Muraven, M., \& Slessareva, E. (2003). Mechanisms of self-control failure: Motivation and limited resources. Personality and Social Psychology Bulletin, 29, 894-906. doi:10.1177/0146167203029007008

Ntoumanis, N., Healy, L. C., Sedikides, C., Duda, J., Stewart, B., Smith, A., \& Bond, J. (2014). When the going gets tough: The "why" of goal striving matters. Journal of Personality, 82, 225-236.

Open Science Collaboration (2015). Estimating the reproducibility of psychological science. Science, 349. doi: 10.1126/science.aac4716

Pageaux, B., Lepers, R., Dietz, K. C., \& Marcora, S. M. (2014). Response inhibition impairs subsequent self-paced endurance performance. European Journal of Applied Physiology, 114, 1095-1105. doi:10.1007/s00421-014-28385

Pageaux, B., Marcora, S., \& Lepers, R. (2013). Prolonged mental exertion does not alter neuromuscular function of the knee extensors. Medicine and Science in Sports and Exercise, 45, 2254-2264. doi:10.1249/MSS.0b013e31829b504a

Pageaux, B., Marcora, S., Rozand, V. \& Lepers, R. (2015). Mental fatigue induced by prolonged self-regulation does not exacerbate central fatigue during subsequent whole-body endurance exercise. Frontiers in Human Neuroscience, 9, 67. doi: 10.3389/fnhum.2015.00067

Price, D. D. (2000). Psychological and neural mechanisms of the affective dimension of pain. Science, 228, 1769-1772. doi:10.1126/science.288.5472.1769 
893 Radel, R., Pelletier, L. G., Pjevac, D., \& Cheval, B. (2017). The links between selfdetermined motivation and behavioral automaticity in a variety of real-life behaviors. Motivation \& Emotion, 41, 443-454

Raichle, M. E., \& Gusnard, D. A. (2002). Appraising the brain's energy budget. Proceedings of the National Academy of Sciences of the United States of America, 99, 10237-

898 10239. doi:10.1073/pnas.172399499

899

Reeve, J., \& Tseng, M. (2011). Agency as a fourth aspect of student engagement during

900 learning activities. Contemporary Educational Psychology, 36, 257-267.

901 doi:10.1016/j.cedpsych.2011.05.00

902 Rhodes, R. E. \& Kates, A. (2015). Can the affective response to exercise predict future motives and physical activity behavior? A systematic review of published evidence. Annals of Behavioral Medicine, 49, 715-731.

905

Rolls, E. T. (2007). Sensory processing in the brain related to the control of food intake.

906 Proceedings of the Nutrition Society, 66, 96-112.

907 doi:http://dx.doi.org/10.1017/S0029665107005332

908 Rotto, D. M. \& Kaufman, M. P. (1988). Effects of metabolic products of muscular 909 contraction on the discharge of group III and IV afferents. Journal of Applied Physiology, 64, 2306-2313

911 Ryan, R. M., \& Deci, E. L. (2006). Self-Regulation and the problem of human autonomy: psychology need choice, self-determination, and will? Journal of Personality, 74, 1557-1585. doi:10.1111/j.1467-6494.2006.00420.x

914 Ryan, R. M., \& Deci, E. L. (2017). Self-determination theory: Basic psychological needs in motivation, development, and wellness. New York, NY: Guilford Press. 
916 Sanders, M. A., Shirk, S. D., Burgin, C. J., \& Martin, L. L. (2013). The gargle effect: Rinsing

917

918

919

920

921

922

923

924

925

926

927

928

929

930

931

932

933

934

935

936

937

938

939

940 Steinberg, L. (2008). A social neuroscience perspective on adolescent riskdoi: 10.1177/0956797612450034

Sappington, R., \& Longshore, K. (2015). Systematically reviewing the efficacy of mindfulness-based interventions for enhanced athletic performance. Journal of Clinical Sport Psychology, 9, 232-262. doi:10.1123/jcsp.2014-0017

Saunders, B., Milyavskaya, M., Etz, A., Randles, D., \& Inzlicht, M. (2018, January 19). function: A Bayesian analysis. Retrieved from psyarxiv.com/bxfsu

Savani, K., \& Job, V. (2017). Reverse ego-depletion: Acts of self-control can improve Psychology, 113, 589-607. http://dx.doi.org/10.1037/pspi0000099

Schlader, Z. J., Simmons, S. E., Stannard, S. R., \& Mundel, T. (2011). The independent roles of temperature and thermal perception in the control of human thermoregulatory behaviour. Physiology of Behavior, 103, 217-224.

Smoliga, Z. S., Mohseni, J. D., Berwager, E. J., \& Hegedus, E. J. (2016). Common causes of dyspnoea in athletes: A practical approach for diagnosis and management. Breathe, 12, e22-e37. doi: 10.1183/20734735.006416

Sripada, C., Kessler, D., \& Jonides, J. (2016). Sifting signal from noise with replication Science. Perspectives in Psychological Science, 11, 576-578. doi:10.1177/1745691616652875.

Starcke, K., Wiesen, C., Trotzke, P., \& Brand, M. (2016). Effects of acute laboratory stress on executive functions. Frontiers on Psychology, 7, 461. doi:https://doi.org/10.3389/fpsyg.2016.00461 the mouth with glucose enhances self-control. Psychological Science, 23, 1470-1472. Reported self-control is not meaningfully associated with inhibition-related executive subsequent performance in Indian cultural contexts. Journal of Personality and Social 

taking. Developmental Review, 28, 78-106. doi:10.1016/j.dr.2007.08.002

942 Tajet-Foxell, B., \& Rose, F. D. (1995). Pain and pain tolerance in professional ballet dancers. British journal of sports medicine ,29, 31-34.

944 doi:http://dx.doi.org/10.1136/bjsm.29.1.31

Taylor, I. M. (2015). The five self-determination mini-theories applied to sport. In S. D. Mellalieu \& S. Hanton (Eds) Contemporary Advances in Sport Psychology, Routledge (pp. 68-90).

Tenenbaum, G. (2001). A social-cognitive perspective of perceived exertion and exertion tolerance. In R. N. Singer, H. A. Hausenblas, \& C. Janelle (Eds.), Handbook of sport psychology (pp. 810-822). New York: Wiley.

951

952

953

954

955

956

957

958

959

960

961

962

963

964

Teper, R., \& Inzlicht, M. (2013). Meditation, mindfulness and executive control: The importance of emotional acceptance and brain-based performance monitoring. Social Cognitive and Affective Neuroscience, 8, 85-92. doi:10.1093/scan/nss045

Teper, R., Segal, Z. V., \& Inzlicht, M. (2013). Inside the mindful mind: How mindfulness enhances emotion regulation through improvements in executive control. Current Directions in Psychological Science, 22, 449-454. doi:10.1177/0963721413495869

Thaler, R. H., \& Sunstein, C. R. (2009). Nudge: Improving decisions about health, wealth, and happiness. London, UK: Yale University Press.

Tooby, J., Cosmides, L., Sell., A., Lieberman, D., \& Sznycer, D. (2008). Internal regulatory variables and the design of human motivation: A conceptual and evolutionary approach. In A. J. Elliot (Ed.), Handbook of approach and avoidance motivation (pp. 136-179). New York, NY: Taylor \& Francis.

Tyler, J. M. \& Burns, K. C. (2008). After depletion: The replenishment of the self's regulatory resources. Self and Identity, 7, 305-321. 
965 Van Custem, J., Marcora, S., De Pauw, K., Bailey, S., Meeusen, R., \& Roelands, B (2017).

966

967

968

969

970

971

972

973

974

975

976

977

978

979

980

981

982

983

984

985

986

987

988 The effects of mental fatigue on physical performance: A systematic review. Sports Medicine, 47, 1569-1588. doi:10.1007/s40279-016-0672-0.

Wagstaff, C. R. D. (2014). Emotion regulation and sport performance. Journal of Sport and Exercise Psychology, 36, 401-412. doi:10.1123/jsep.2013-0257

Walsh, V. (2014). Is sport the brain's biggest challenge? Current Biology, 24, 859-860. doi:10.1016/j.cub.2014.08.003

Weinstein, N., Deci, E. L., \& Ryan, R. M. (2011). Motivational determinants of integrating positive and negative past identities. Journal of Personality and Social Psychology, 100, 527-544. doi:10.1037/a0022150

Werner, K. M., Milyavskaya, M., Foxen-Craft, E., \& Koestner, R. (2016). Some goals just feel easier: Self-concordance leads to goal progress through subjective ease, not effort. Journal of Personality and Individual Differences, 96, 237-242. doi:10.1016/j.paid.2016.03.002

Whiteside, S. P., \& Lynam, D. R. (2001). The five factor model and impulsivity: Using a structural model of personality to understand impulsivity. Personality and Individual Differences, 30, 669-689. doi:10.1016/S0191-8869(00)00064-7

Woolley, K., \& Fishbach, A. (2016). Immediate rewards predict adherence to long-term goals. Personality \& Social Psychology Bulletin, 43, 151-162. doi: $10.1177 / 0146167216676480$

Wright, R., Junious, T., Neal, C., Avello, A., Graham, C., Herrmann, L., \& Walton, N. (2007). Mental fatigue influence on effort-related cardiovascular response: Difficulty effects and extension across cognitive performance domains. Motivation and Emotion, 31, 219-231. doi:10.1007/s11031-007-9066-9 
989 Wright, R. A., Stewart, C. C., \& Barnett, B. R. (2008). Mental fatigue influence on effortrelated cardiovascular response: extension across the regulatory (inhibitory)/nonregulatory performance dimension. International Journal of Psychophysiology, 69:

992 $127-133$.

993 Zou, Z., Liu, Y., Xie, J., \& Huang, X. (2016). Aerobic exercise as a potential way to

994 improve self-control after ego-depletion in healthy female college students. Frontiers

995 in Psychology, 7, 501. doi:https://doi.org/10.3389/fpsyg.2016.00501 